\title{
Descriptive analysis of immunization policy decision making in the Americas
}

\author{
Julianne E. Burns, ${ }^{1}$ Rachel C. Mitrovich, ${ }^{1}$ Barbara Jauregui, ${ }^{1}$ \\ Cuauhtémoc Ruiz Matus, ${ }^{1}$ and Jon K. Andrus ${ }^{1}$
}

ABSTRACT Objectives. Reducing and eliminating vaccine-preventable diseases requires evidencebased and informed policy decision making. Critical to determining the functionality of the decision-making process for introduction of a new vaccine is understanding the role of the national immunization technical advisory group (ITAG) in each country. The aim of this study is to document the current situation of national level immunization policy decision making for use in the Pan American Health Organization (PAHO) ProVac Initiative.

Methods. A structured 66-variable questionnaire developed by the World Health Organization (WHO) in collaboration with the University of Ottawa was distributed to all WHO regions; it was composed of dichotomous, multiple-choice, and open-ended questions. Questionnaires were e-mailed or faxed to the six WHO regional offices and the offices distributed them to all member states. This paper analyzes surveys from the Americas as part of PAHO's ProVac Initiative.

Results. Twenty-nine countries of the Americas answered the survey. They conveyed that immunization policy making needed to be improved and further supported by organizations such as PAHO. Areas of improvement ranged from organization and technical support to strengthening capacity and infrastructure to improved coordination among stakeholders. This survey also highlighted a variety of ITAG processes that need further investigation.

Conclusion. This survey supports the efforts of PAHO's ProVac Initiative to disseminate knowledge and best practices for an immunization policy decision-making framework through the development of clear definitions and guidelines. By highlighting each problem noted in this study, ProVac will assist countries in Latin America and the Caribbean to build national capacity for making evidence-based decisions about introduction of new vaccines.

Key words Immunization; policy making; decision making; advisory committees; Latin America.

Achieving the greatest sustainable impact in eliminating vaccine-preventable diseases requires evidence-based and in-

\footnotetext{
Pan American Health Organization, Family and Community Health Area, Immunization Unit, United States of America. Send correspondence and reprint requests to: Barbara Jauregui, Pan American Health Organization, Family and Community Health Area, Immunization Unit, 525 23rd Street NW, Washington, DC 20037, United States of America; phone: 202-974-3413; fax: 202-974-3635; e-mail: jauregub@paho.org
}

formed policy decision making. Variation in resource availability and burden of disease among countries and subregions must be reflected in any such immunization policy decision (1). Recently, efforts to help countries increase their national capacity to make evidencebased decisions have intensified, especially with regard to vaccine introduction. However, in order to develop targeted strategies for improving the ex- isting policy decision-making process for introduction of new vaccines, the current situation must be better understood.

In response to the need for a situational analysis, the World Health Organization (WHO), in conjunction with WHO regions, the University of Ottawa, and the Public Health Agency of Canada, developed and distributed a questionnaire on the national level immunization policy decision-making pro- 
cess (2). Critical to determining the functionality of the decision-making process for the introduction of new vaccines is understanding the role of the national technical advisory groups (ITAG) in countries. The questionnaire not only documented the current situation of national level immunization policy decision making, but it also provided the opportunity for countries to address principal challenges encountered, improvements needed, and support requested from the organization.

The aim of this study is to document the current situation of national level immunization policy decision making to strengthen the Pan American Health Organization (PAHO) ProVac Initiative's activities and implementation plan. The goal of the ProVac Initiative is to strengthen the national capacity to make evidence-based decisions about the introduction of new vaccines in Latin America and the Caribbean. ProVac is developing best practices for essential technical support for countries within the region, particularly for strengthening infrastructure and processes that are critical for making decisions to implement new vaccines in the countries of the Americas (3).

\section{MATERIALS AND METHODS}

In March 2008, a structured 66-variable questionnaire was distributed to all WHO regions. The aim of the questionnaire was to document the processes countries use when making recommendations about vaccines in routine immunization schedules. Questionnaires were distributed to WHO regional offices via e-mail or fax and were returned to WHO in a similar fashion. This paper analyzes surveys from the Americas.

A draft questionnaire was circulated to WHO staff in the regional offices as well as to a few experts in immunization policy development for feedback. This procedure also provided the opportunity for suggestions for including specific information they would like collected on the topic. The questionnaire was modified to incorporate this feedback. The questionnaire was pilot tested in February 2008 in six countries in Africa and modified accordingly. The final revised questionnaire was distributed in March 2008 by WHO headquarters through WHO regional offices to all countries. The survey and follow-up letters were distributed by e-mail between March and July 2008. Up to four reminder letters were sent to nonresponders before the final submission date of July 1, 2008.

The questionnaire included dichotomous, multiple-choice, and open-ended questions. The first section of the questionnaire, using mainly closed questions, focused on the processes used by the Ministry of Health (MOH) in developing immunization policies, the various players working with the government, and the sources of information used when developing these policies. To better understand the policy-making environment in each country, respondents were asked open-ended questions about the challenges, desired changes, and what-if any-support was desired from WHO. Multiple-choice and open-ended questions could not yield mutually exclusive answers as countries were asked to check or list all responses that applied. Openended questions queried respondents about their concerns, challenges, experiences, and specific details of the immunization policy decision-making process.

The questionnaire had seven sections, but sections $2-7$ were completed only by countries that had an ITAG. Respondents that completed the entire survey were asked to attach the ITAG's terms of reference and functions, minutes from their most recent ITAG meeting, and a list of tools used in the recommendation process for further analysis. The survey was targeted to the Expanded Program of Immunization (EPI) manager or to individuals with knowledge of immunization decision-making processes.

\section{RESULTS}

\section{Responses}

The questionnaire was distributed to all six WHO regions, but only the surveys from the Region of the Americas are analyzed in this study. It is expected that WHO will publish the results from all regions in the second semester of 2009.

This questionnaire was distributed to 35 countries in the PAHO region. By July 2008 , PAHO had an $82.9 \%$ return rate; 29 completed questionnaires were analyzed. Five countries $(14.3 \%$ ) did not return their questionnaires and Haiti submitted a description of existing immunization committees in lieu of the distributed questionnaire. The targeted respondent for the questionnaire was an EPI manager or individual with knowledge of the immu- nization decision-making processes. EPI managers were most likely to fill out the questionnaire $(75.9 \%)$. Ten percent of the questionnaires were completed by another $\mathrm{MOH}$ official, followed by $6.9 \%$ completion by other professionals in the medical field.

\section{Governmental cross-sectional coordination}

When asked to name the ministries of government involved in the decisionmaking process for immunization, $93.1 \%$ of responders listed the MOH. The Ministry of Finance was involved $44.8 \%$ of the time, followed by the Ministry of Education $(20.7 \%)$, and Social Development (13.8\%). These responses were not mutually exclusive. Of the 29 countries that returned the questionnaire, $17(58.6 \%)$ reported that they had a national ITAG for all vaccine-preventable disease and $12(41.4 \%)$ did not. Some countries with an ITAG also had a disease-specific group (Table 1).

\section{Countries without an ITAG}

All 12 countries that indicated they did not have an ITAG were located in the Caribbean. These countries receive guidelines from an annual Caribbean EPI manager's meeting. Within this group, three countries reported the existence of a disease-specific ITAG that expanded immunization policies beyond the recommendations of the annual Caribbean EPI manager's meeting.

To further address evidence sources used in the Caribbean, countries were surveyed on the processes the $\mathrm{MOH}$ uses to determine which immunization recommendations to adopt. Ninety-two percent of countries stated in a multiple-choice question that they follow guidelines put forth by $\mathrm{PAHO}, 83.3 \%$ stated that their decisions are made within the $\mathrm{MOH}$, and $66.7 \%$ said that they follow guidelines from WHO headquarters. Additionally, $50 \%$ said that they follow guidelines from a regional ITAG and $33.3 \%$ rely on recommendations of a national ITAG. With regard to sources of information used in making immunization policy decisions, $75 \%$ of countries without ITAGs indicated that they use WHO vaccine position papers and $75 \%$ reported using $\mathrm{PAHO}$ intercountry meeting reports and recommendations. Government reports and published studies were used by $58 \%$ and 
TABLE 1. Countries in the Americas with and without disease-specific technical advisory groups, 2008

\begin{tabular}{lll}
\hline & ITAG ${ }^{\text {p present }}$ & \multicolumn{1}{c}{ ITAG not present } \\
\hline Does not have disease-specific & Colombia & Anguilla \\
technical advisory board & Guatemala & Belize \\
& Honduras & Guyana \\
& Nicaragua & Jamaica \\
& Panama & Montserrat \\
& Paraguay & St. Vincent and the Grenadines \\
& Barbados & Suriname \\
& Canada & Trinidad and Tobago \\
& United States & Bahamas \\
& Puerto Rico & \\
Disease-specific technical & Argentina & Dominica \\
advisory board in place & Bolivia & Dominican Republic \\
& Cuba & Grenada \\
& El Salvador & \\
Venezuela & \\
Total & Brazil & \\
\hline
\end{tabular}

a ITAG = national immunization technical advisory group.

$33.3 \%$ of the countries, respectively. National committee statements and country level interagency coordinating committees were considered a source of information $25 \%$ of the time.

\section{Countries with an ITAG}

All 17 countries that reported having ITAGs established them after 1996, with the exception of Canada and the United States of America (1960s), Cuba (1989), and Brazil (1991).

Function. Of those 17 countries, $88.2 \%$ reported that their ITAG assists the government in establishing immunization poli- cies, $70.6 \%$ reported that their ITAG informs the government of the public health needs for vaccine, and $64.7 \%$ reported that their ITAG assists the government in addressing issues of vaccine quality, safety, and evaluation of new vaccines. In $35.3 \%$ of the countries, the ITAG also promotes regional and national vaccine security and the evaluation of new immunization technologies. These results were not mutually exclusive.

Sources of information. In countries with an ITAG, the MOH relies on recommendations of the national ITAG $100 \%$ of the time. Countries with an ITAG and those without follow guidelines from
PAHO $82.3 \%$ and $92 \%$ of the time, respectively. A little more than half the respondents $(52.9 \%)$ reported that they follow guidelines from WHO headquarters. Of those nine countries, seven follow guidelines from $\mathrm{PAHO}$ regional headquarters.

Approximately $82.4 \%$ of countries with an ITAG use other external committees when making immunization policy decisions as well as WHO vaccine position papers, intercountry meeting reports and recommendations, and published studies. National committees that exist outside of ITAGs were consulted by $76.5 \%$ of respondents and unpublished research conducted in the home country was referenced by $58.8 \%$ of the countries participating. Government reports and country level interagency coordinating committees were reported by $47.1 \%$ and $29.4 \%$, respectively. Unlike countries without ITAGs that took other countries' and neighboring countries' decisions into consideration when making policy decisions, countries with ITAGs did not.

Logistics. The logistics of ITAGs varied. Formal terms of reference were executed in $82 \%$ of the respondents. Of the 17 countries with an ITAG, $76.5 \%$ had a legislative or administrative basis for their ITAGs. Forty-one percent received funding and support from outside sources. Only $29.4 \%$ indicated that their ITAG members signed a declaration of potential conflict of interest (Figure 1).

Composition of the ITAG. Approximately $94.1 \%$ reported having an epi-

FIGURE 1. Immunization technical advisory group logistics description, the Americas, 2008

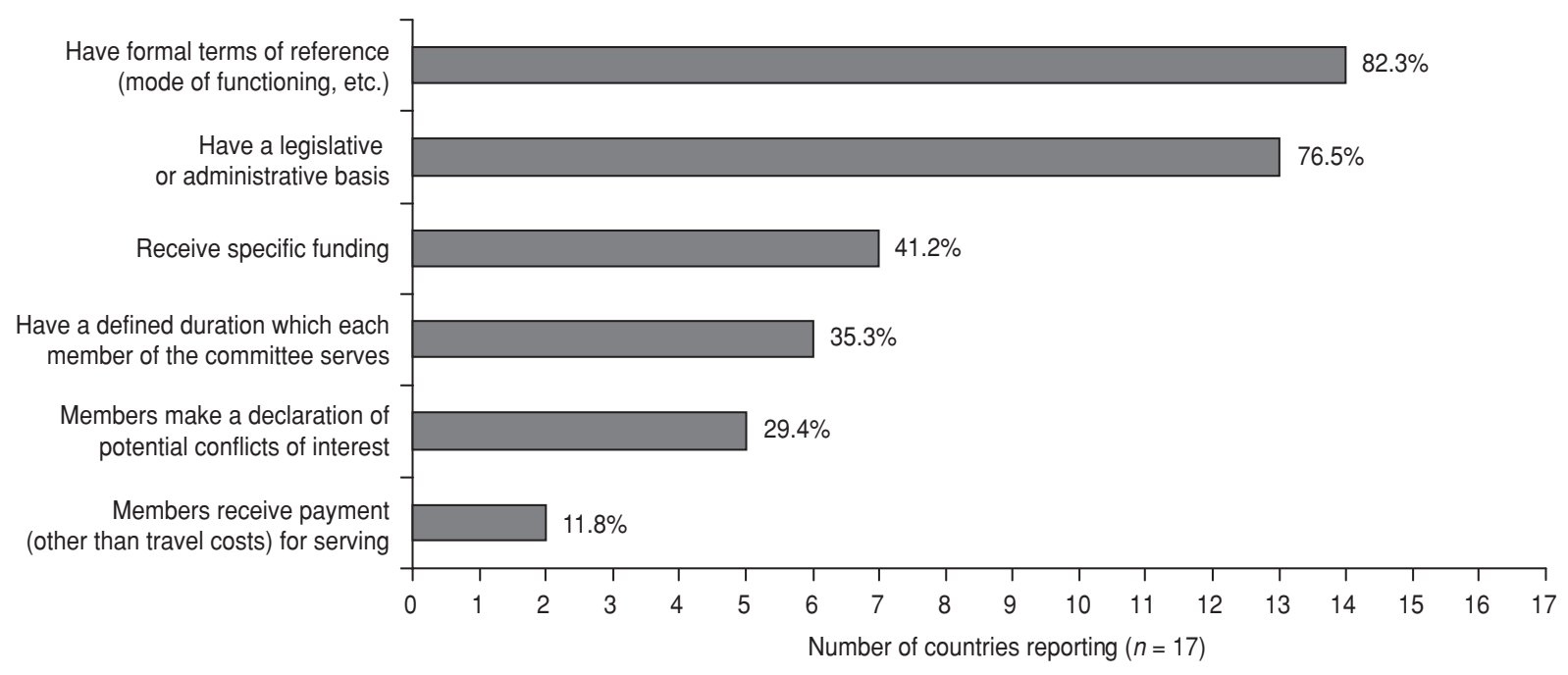


FIGURE 2. Professions or areas of expertise represented on national immunization technical advisory groups, the Americas, 2008

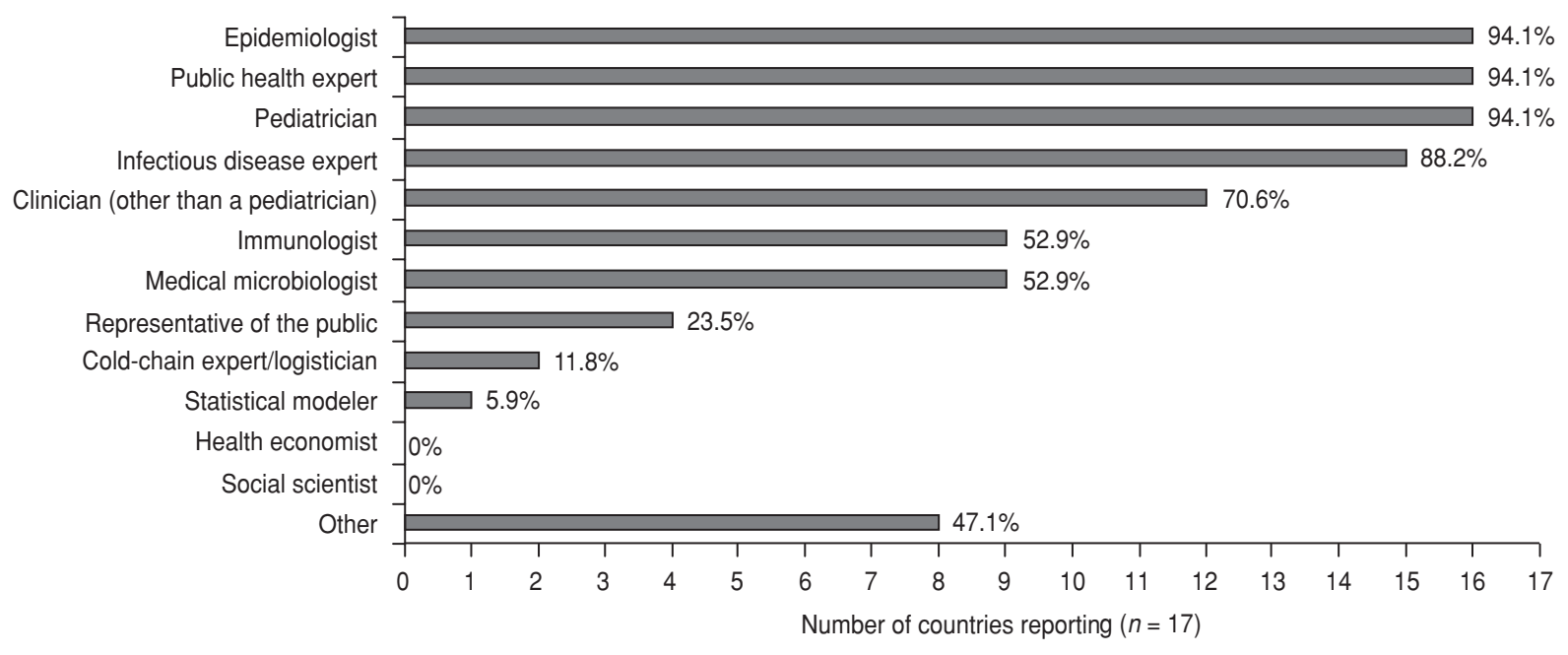

demiologist, public health expert, or pediatrician on their ITAG. An infectious disease expert participated in $88.2 \%$ of the countries and a clinician (other than a pediatrician) participated in $70.6 \%$ of ITAGs. Microbiologists were present $52.9 \%$ of the time and a representative of the public was present $23.5 \%$ of the time (Figure 2).

Countries also reported a variety of ITAG liaison members who provide input but do not participate in the immunization decision-making process. Liaison members are present at meetings to bring knowledge to technical advisory group discussions and to express the views of the organization they represent. Seventy-six percent of the countries reported that they had liaison members from academic or professional organizations, $76.5 \%$ from international organizations, and $70.6 \%$ from other countries and government departments. Individuals from nongovernmental organizations and from pharmaceutical organizations served as liaisons in $41.2 \%$ and $35.3 \%$ of the reporting countries, respectively. Eighty percent of countries that said they did not have liaison members went on to answer questions about the organizations that liaison members belonged to.

Decision-making process. Of the 17 countries with an ITAG, all took into account disease burden in their country and vaccine efficacy when considering recommendations. Vaccine safety and the economic impact of the disease were also key factors in 16 of the 17 countries surveyed $(94.1 \%)$. Seventy-one percent of countries stated that the priority of the vaccine related to other vaccine-preventable diseases was considered. The priority of the vaccine related to other public health interventions and the public perception of the disease was taken into account in $52.9 \%$ of the countries. Twenty-nine percent of countries believed the method of vaccine administration was a factor. Only $11.8 \%$ stated that disease burden in neighboring countries was considered.

Dissemination of ITAG recommendations. Countries described a variety of ways their ITAG recommendations are communicated to the $\mathrm{MOH}$, to the public, and to practicing health professionals. Recommendations reach the $\mathrm{MOH}$ through committee reports, records, or presentations. They are also communicated through consultations or directly through a committee representative such as the national program coordinator. Recommendations are announced to the public through publications, documents, websites, and press communications. In some cases, workshops or meetings with specialized groups may be involved. Of the 17 countries with an ITAG, $41.2 \%$ of respondents stated that the minutes of the ITAG meeting were confidential; $11.8 \%$ said the meetings were closed. Practicing health professionals are notified of recommendations via documents, publications, journals, and websites. Information may also be presented through meetings, workshops, or press communication targeting the private sector. Two of the 17 countries reported that information is never communicated to practicing health professionals in their country.

\section{Opportunities for improving the immunization decision-making process}

All 29 reporting countries suggested ways their immunization policy-making process could be improved (Table 2). Countries specifically requested support in the following areas.

Building infrastructure: support for development of an ITAG. All 12 countries that stated they did not have a national ITAG indicated they would like to establish one. Ten of these 12 countries $(82.4 \%)$ expressed the desire to establish an ITAG with clearly written policies and representation from diverse institutions. The same countries suggested that WHO support the development of technical guidelines, facilitate the selection of who will serve on the committee, and provide guidance on conducting meetings.

System strengthening: support to improve existing ITAGs. All 17 ITAG countries cited ways their immunization policy-making process and existing ITAG could be improved (Table 2). Four countries $(23.5 \%)$ cited the need for guidance on ITAG terms of reference, composition, coordination, and information dissemination. Two (11.8\%) suggested that the scientific knowledge of committee members on immunizations should be strengthened and membership diver- 
TABLE 2. Country suggestions in the Americas for continued support and strengthening of immunization policy making, 2008

\begin{tabular}{|c|c|c|c|c|}
\hline \multirow{2}{*}{$\begin{array}{l}\text { Countries specifically requested support } \\
\text { and improvements in the following areas: }\end{array}$} & \multicolumn{2}{|c|}{ Have ITAGa $(n=17)$} & \multicolumn{2}{|c|}{ Do not have ITAG $(n=12)$} \\
\hline & Number & Percent & Number & Percent \\
\hline Building infrastructure: support development of an ITAG & 0 & 0.0 & 12 & 100.0 \\
\hline System strengthening: improve existing ITAG & 17 & 100.0 & 0 & 0.0 \\
\hline Improving coordination among stakeholders & 6 & 35.3 & 3 & 25.0 \\
\hline Increasing awareness or political commitment & 3 & 17.6 & 5 & 41.7 \\
\hline Strengthening data collection systems & 9 & 52.9 & 5 & 41.7 \\
\hline Securing vaccine financing & 5 & 29.4 & 4 & 33.4 \\
\hline Generating economic evaluations & 7 & 41.2 & 4 & 33.4 \\
\hline Obtaining financial assistance & 4 & 23.5 & 2 & 16.7 \\
\hline
\end{tabular}

a ITAG = national immunization technical advisory group.

sified. Four additional countries $(23.5 \%)$ cited the need to reduce conflicts of interest among membership, provide compensation for their members, or increase member commitment. Increased commitment was defined as enhanced attendance or preparation before the meeting. Furthermore, 13 countries $(76.5 \%)$ indicated that WHO should continue to provide technical assistance, economic guidance, and financial advice.

Improve coordination among stakeholders. All 29 countries (regardless of ITAG status) responded to questions addressing the need to improve national coordination of vaccine policy stakeholders. Suggested improvements included increasing communication across governmental departments, cross-country organization, and standardization of vaccine policies. Enhanced coordination with private health care practitioners and vaccine manufacturers, especially for increasing the availability of vaccine clinical trial data, was also cited in recommendations. Nine of the 29 countries (31\%) specifically requested improved governmental coordination of vaccine policies.

Strengthen data collection systems. Deficiencies in disease surveillance systems were reported by 14 countries (48.3\%) as areas for improvement. With a lack of quality surveillance data at the regional and municipal levels, these countries found it difficult to determine the burden of vaccine-preventable diseases, especially where new vaccines have become available. The same 14 countries reported the desire to place greater emphasis on disease prevalence when making immunization policy decisions and to strengthen their surveillance systems to obtain accurate information. Other recommendations included a greater integration of data collection systems, expansion of geographic indications for vaccinations, technical support for studies, and guidelines.

Generation of economic evaluations. Eleven countries $(37.9 \%)$ cited a lack of economic studies on vaccinations, such as cost-benefit or cost-effective analysis, especially for new vaccines. They indicated that, with standardized economic analysis, more informed immunization policy decisions can be made. Furthermore, 10 of the 11 countries stated the need to train ITAG members in the generation and interpretation of these economic studies.

Financial assistance. A lack of sufficient financial resources to assist with the cost of vaccines and associated costs, such as for equipment to improve cold-chain capacity (transportation and vaccine storage prepared for temperature-labile products), was cited as a major concern. Nine of the 29 countries $(31.0 \%)$ stated the need to guarantee sustainability and financial security of vaccine programs by creating laws that establish lines within national health budgets for the purchase of recommended vaccines. The lack of permanent funding fosters difficulty in long-term program forecasting and sustainable economic feasibility. The use of ITAG member volunteers who are not compensated for their time was also expressed as a financing concern.

Increase awareness and political commitment. Countries recognized the need for greater awareness, both of the public on the benefits of vaccination and of the $\mathrm{MOH}$ and health professionals on the relevance of immunization programs. Two of the 29 countries $(6.9 \%)$ cited the need for greater public awareness of vaccination benefits. Two additional countries (6.9\%) suggested that WHO provide support through publishing documents in order to facilitate greater awareness. Four countries (13.8\%) suggested increasing the availability of clinical trial data from vaccine manufacturers and one country $(3.4 \%)$ introduced the need to change the attitude of vaccination critics.

Three of the 29 countries (10.3\%) cited political opposition or a lack of political will as hindering the creation of immunization policy. One country (3.4\%) mentioned an entanglement of political opposition to governmental health policy, and another $(3.4 \%)$ stated a general lack of political will.

\section{DISCUSSION, RECOMMENDATION, AND FUTURE ACTION STRATEGIES}

Limitations of this study included a lack of opportunity for equal evaluation of the immunization policy decisionmaking process in countries with and without an ITAG, as countries without an ITAG were excluded after they completed the first section of the questionnaire. Multiple-choice options were rarely mutually exclusive, and the order varied in different language versions. In some cases, there were inconsistencies in responses.

Occasionally, exact phrasing taken from a previous question appeared in a country's response to an open-ended question. This act may have biased questionnaire results toward how WHO thinks countries should improve immunization policy decision making instead of reflecting accurate conditions. As all questionnaires were not completed by national immunization program coordinators, who might provide the most ac- 
curate information, reporter bias may be another limitation of this questionnaire. Additionally, lack of response by some countries of the Americas may hinder the ability of these results to be generalized to the entire region. A scale measuring the strength of needed support should also be included in future studies.

While this survey was the first known collection of information on ITAGs, the results highlight a variety of ITAG processes that need further investigation. One area that was not addressed is the role of the vaccine manufacturer in an ITAG decision process. As noted, most members are not asked to make explicit their conflicts of interest or affiliation with the manufacturing sector. The respondents reported that approximately one-third of the ITAGs use documents generated by the pharmaceutical companies as one of the sources to guide their recommendations. Also, there are countries that do not produce ITAG meeting notes or disclose any information to the public or professionals in the field. This relationship must be transparent to ensure the credibility of the ITAG (4).

Additionally, this analysis served to identify several key findings about the decision-making process in the region. Most countries reported that the several governmental and nongovernmental bodies external to the $\mathrm{MOH}$ are involved in the decision-making process regarding immunization. Many countries stated the need to improve national coordination of vaccine policy stakeholders. Specific areas included increasing communication across governmental departments, cross-country organization, and standardization of vaccine policies.

Deficiencies in epidemiologic data collection and surveillance systems were also reported. With a lack of quality data and reliable information on immunization coverage, many found it difficult to determine the burden of vaccine-preventable diseases, especially those for which new vaccines were available. Countries reported the desire to strengthen and integrate data collection systems, so more accurate information can be obtained and greater emphasis can be placed on disease prevalence when making immunization policy decisions.

None of the ITAGs that responded to the survey has a health economist as a member. The need to assess the financial sustainability of vaccine programs was a significant issue brought to the forefront by this questionnaire, suggesting that economic assessments have become an integral part of policy decision making in health care (5). Countries also indicated the need to guarantee sustainable, financial security of their vaccine programs. Respondents stated that could be done by creating or expanding existing legislation for a national health budget line to include the purchase of recommended vaccines (6). For countries that lack a legal designation of resources for vaccines, long-term program forecasting and sustainable economic feasibility is unrealistic. While implementing vaccine-specific laws, countries should also enhance fiscal space in the existing budget so new vaccines can be sustained in national schedules without economic limitations (7).

Achieving the greatest sustainable impact in eliminating vaccine-preventable diseases requires evidence-based and informed policy decision making. Variations in resource availability and burden of disease between countries and subregions must be reflected in any such immunization policy decisions.

The WHO questionnaire has been a very useful exercise to understand the current situation of national level immunization policy decision making in countries of the Americas. Additionally, the questionnaire has provided an opportunity for countries to document the main challenges encountered, improvements needed, and support requested from WHO. All 29 countries that completed the questionnaire cited ways their immunization policy making can be improved.

This questionnaire has been important in helping to strategize technical assistance from $\mathrm{PAHO}$ in strengthening country-level capacity to make evidencebased decisions. Improving processes for policy making will help to ensure that immunization decisions are reached through rigorous and informed deliberations. Synthesizing knowledge from a diverse range of experts, utilizing a variety of information sources, and increasing transparency in decision making will encourage implementation of the most utilitarian recommendations.

PAHO's ProVac Initiative will incorporate the study's results in order to best provide the essential technical support that countries have requested, both in strengthening infrastructure and in processes for decision making. A partnership of technical cooperation task forces led by PAHO will bring together national and subregional surveillance groups, experts from other disciplines, and key stakeholders to improve epidemiologic surveillance systems. In addition, establishing a network of key centers of excellence specialized in health costing will ensure that health economists are available to aid countries in the generation and analysis of economic evaluations.

After performing a situational analysis, ProVac will facilitate the implementation of an ITAG or enhance the effectiveness of an existing group by improving composition and coordination with other stakeholders, diversifying factors considered when making recommendations, and increasing accountability. In some cases, a subregional approach may be the most effective method for capacity development.

Through distance learning and site visits, ProVac will also support the development of "white papers," which will serve as working documents to help countries prioritize the areas of policy decision making that need strengthening (8).

Improving processes for policy making will help to ensure that immunization decisions are reached through rigorous and informed deliberations. Synthesizing knowledge from a diverse range of experts, utilizing a variety of information sources, and increasing transparency in decision making will encourage the implementation of programs that are feasible and effective, thus increasing chances for success. 


\section{REFERENCES}

1. Andrus JK, Dietz V, Fitzsimmons JW, CastilloSolorzano C. Accelerating policy, development and access to new and underutilized vaccines in developing countries. Harvard Health Policy Rev. 2006;7(2):91-101.

2. The World Health Organization. Report of the Strategic Advisory Group of Experts (SAGE). Geneva: WHO; 2009. Available from: http:// www.who.int/immunization/policy/sage_ recomm_who.pdf. Accessed 13 April 2009.

3. Andrus JK, Toscano CM, Lewis M, Olivieria L, Ropero AM, Davila M, et al. A model for enhancing evidence-based capacity to make informed policy decisions on the introduction of new vaccines in the Americas: PAHO's Pro
Vac Initiative. Public Health Rep. 2007;122(6): 811-6.

4. Hessel L. The contribution of vaccine manufacturers to the establishment of vaccination policies. J Public Health. 2008;16(4):299-305.

5. Meltzer MI. Introduction to health economics for physicians. Lancet. 2001;358(9286):993-8.

6. Pan American Health Organization. Immunization newsletter. Regional strategy for sustaining national immunization in the Americas. Washington, DC: PAHO; 2009. Available from: http://www.paho.org/English/AD/FCH/ IM/sne2805.pdf. Accessed 13 April 2009.

7. Dempsey AF, Cowan AE, Stokley S, Messonnier M, Clark SJ, Davis MM. The role of eco- nomic information in decision-making by the Advisory Committee on Immunization Practices. Vaccine. 2008;26(42):5389-92.

8. Pan American Health Organization. Immunization newsletter. The ProVac Initiative. Washington, DC: PAHO; 2009. Available from: http://www.paho.org/English/AD/FCH/ IM/sne2805.pdf. Accessed 13 April 2009.

Manuscript received on 16 April 2009. Revised version accepted for publication on 9 September 2009

RESUMEN Objetivos. Para reducir y eliminar las enfermedades prevenibles por vacunación se requiere tomar decisiones basadas en datos científicos y una política informada. Con el fin de determinar la funcionalidad del proceso de toma de decisiones para intro-

Análisis descriptivo de la toma de decisión sobre políticas de vacunación en las Américas

ducir una nueva vacuna es vital comprender el papel de los grupos técnicos asesores nacionales sobre vacunación (GTAN) de cada país. En este trabajo se documenta la situación actual de la toma de decisión sobre políticas de vacunación a nivel nacional como insumo de la Iniciativa ProVac de la Organización Panamericana de la Salud (OPS).

Métodos. Se distribuyó a todas las regiones de la Organización Mundial de la Salud (OMS) un cuestionario estructurado con 66 variables, desarrollado por la OMS en colaboración con la Universidad de Ottawa, Canadá. El cuestionario contenía preguntas abiertas, dicotómicas y de selección múltiple y se envió por correo electrónico o fax a las seis oficinas regionales de la OMS y estas lo distribuyeron a todos los estados miembros. En este manuscrito se analizan las respuestas procedentes de las Américas, como parte de la Iniciativa ProVac de la OPS.

Resultados. Respondieron la encuesta 29 países de las Américas. Todos coincidieron en que la formulación de políticas de vacunación debe mejorar y se necesita más apoyo de organizaciones como la OPS. Las áreas que requieren mejoras van desde la organización y el apoyo técnico hasta el fortalecimiento de la capacidad y la infraestructura, y el perfeccionamiento de la coordinación entre los diferentes actores. También se destacan algunos procesos de los GTAN que requieren mayor investigación. Conclusión. Esta encuesta apoya los esfuerzos de la iniciativa ProVac de la OPS para diseminar el conocimiento y las mejores prácticas para elaborar un marco de trabajo para la toma de decisiones sobre políticas de vacunación mediante el desarrollo de definiciones y directivas claras. Al poner de manifiesto cada problema observado en este estudio, ProVac contribuye a que los países de América Latina y el Caribe eleven su capacidad nacional para tomar decisiones sobre la introducción de nuevas vacunas a partir datos científicos.

Palabras clave América Latina. 